\title{
Somatic Status, Stress Levels and Energy Expenditure Pattern of Adult Women
}

\author{
Sowmya G. Rao* and Shashikala Puttaraj \\ Department of Studies in Food Science and Nutrition, Manasagangothri, \\ University of Mysore, Mysore 570 006, Karnataka, India \\ *E-mail: rao.sowmya@yahoo.com
}

KEYWORDS Adult Women. Somatic Status. Abdominal Obesity. Energy Intake. Energy Expenditure

\begin{abstract}
Recent research on women's health and nutritional status have indicated disturbing trends related to malnutrition due to excess energy intake or impaired energy balance leading to overweight/obesity, particularly among those women who are physically inactive. Further, those women who are gainfully employed are subjected to additional stress due to their diverse economic, reproductive and cultural roles, which can have a detrimental effect on their nutrition and health. The present study assessed the nutritional status of 40 normal adult women in the age group of 20-60 years residing at different locales of Mysore city of Karnataka State. While somatic status of these women was assessed by Anthropometric measurements (Height, Weight, Mid upper arm circumference (MUAC), Skin Fold Thickness (SFT)), their energy expenditure was computed by a Factorial method using activity level and time records of two consecutive days and also using a Pedometer. The results indicated a positive energy balance in all age groups with concomitant increase in Body mass index. The energy, protein and fat status remained normal up to 40 years of age and increased thereafter. Waist Hip ratio (WHR), a risk factor for the development of chronic diseases increased as age advanced. However the energy intake of women was lower than the recommended dietary intake. The tendency towards reduced physical activity reflected in their increasing weight resulting in overweight with advancing age. It is suggested that studies such as these are required to predict the risk of developing non-communicable diseases in normal population.
\end{abstract}

\section{INTRODUCTION}

In the developing countries, with increasing urbanization, mechanization of jobs and transportation, availability of processed and fast foods, and dependence on television for leisure, people are fast adopting less physically active lifestyles and consuming more "energy-dense, nutrientpoor" diets. As a result, overweight, obesity and many chronic health problems are increasing rapidly, particularly among the middle-class, urban populations. Even in countries like India, which are typically known for high prevalence of under nutrition, significant proportions of overweight and obese now coexist with the undernourished (Vinod 2004).

Numerous studies have demonstrated a role for body weight in morbidity and mortality risk among women, including diabetes, cardiovascular disease and arthritis. The prevalence of being overweight increases from the age of 20 to 60 years (Sammel et al. 2003).

Indian population is passing through a transition phase where subsistence conditions are being replaced by plentiful food but reduced physical work and therefore, an understanding of the changing nutritional scene is critical (Shobha 2001).
Women work more at home as well as at the work place, to take care of the families particularly men and children (Capoor and Chetana 2000). The dual role of women as 'income earner' and 'family caretaker' has recently emerged as an important determinant of women's own nutrition. An important part of a women's status is her material fulfillment that depends on her own income, family income and her control over the income. Additional female earnings may increase total family income but may not necessarily increase women's access to such income and as a result, it may not be a sufficient force for improvement in her own status (Food and Nutrition Bulletin 2006). Hence the present study was undertaken to determine the Somatic status, stress levels and energy expenditure patterns in Adult women.

\section{MATERIALS AND METHODS}

The present study was undertaken in Mysore city, Karnataka state. Forty women subjects within the ages of 20-60 years with no underlying disorders or morbidities were selected randomly from the urban population of Mysore city. An attempt was made to enroll an equal number of subjects in each group of i.e. 20-30, 31-40, 41-50 and 51-60 years. 
A preformed questionnaire was used to record personal data, anthropometric measurements, dietary intake, activity record, and stress scores of the selected women.

The food intake of all the women was assessed by interviewing the women with the help of household measures relevant to Indian cuisine models to construct the individual women's 24 hour food intake. Raw amounts for the cooked food items were derived by standardizing the preparatory methods of different menu items. The total energy intake was derived by the amount of macronutrients included in the diet (Gopalan 1993). The energy intake of the women was compared against recommended dietary intake for ensuring the appropriateness of intake derived based on the Recommended dietary allowances for age, gender and activity (Indian Council of Medical Research 1987).

Anthropometric measurements- Height $(\mathrm{cm})$, Weight (kg), Arm circumference $(\mathrm{cm})$, Waist $(\mathrm{cm})$, Hip (cm), Triceps Skin Fold (mm) measurements using the standard procedure (Jelliffe 1966 and Encylopaedia 1993 ) were recorded for all the 40 subjects.

Energy expended in different activities for two consecutive days was computed using the data on time use recalls of the subjects as per the Food and Agriculture Organization/World Health Organization estimates (WHO 1985) of energy required per minute for specified class of activities.

Estimation of energy expenditure was also done using Pedometer. Energy expenditure using pedometer was compared with the factorial approach.

The subjects were instructed to use Pedometer designed by Titan Industries Limited. An attempt was made to validate the estimation of daily energy expenditure by the pedometer developed for the Indian population by the company against a factorial approach that is commonly used in the field and research studies in India today.

The pedometer was set with all the necessary input variables and the operation was explained to the subjects. However, the subjects were discouraged from changing the settings on their own to avoid errors in the entry of data. The correct placement of the pedometer for accurate measurement of steps while in operation was, perpendicular to the ground, and the subjects wore the pedometer right side of the hip area inline with the knee.
The subjects were instructed to have the pedometer fixed on their waist bands through out the day except for sleeping and bathing. Typical work and leisure routines were followed by the subjects during the course of the study. Pedometer readings were recorded on two separate days. To avoid changes in the normal routine of physical activity, measurements were not taken on weekends or holidays/festivals.

The data was tabulated and subjected to appropriate statistical analysis.

\section{RESULTS}

General Information: Normal and healthy adult women belonging to middle income group in the age group of 20-60 years were included in the present study. An attempt was made to include equal number of subjects in each group. The background information of the subjects is presented in Table 1. Majority of the women belonged to nuclear family. Fifty percent of the women were confined to household work and other $50 \%$ were engaged in teaching and office work (non-executives). Majority of families had a household size of four.

Somatic Status: The mean anthropometric measurements classified according to age groups are shown in Table 2 . The results showed that there was a constant increase in weight overtime from 21-60 years. The weight ranged from 57-60 $\mathrm{Kgs}$. Body mass index, an indicator of energy status showed an increase as the age advanced. Normal body mass index was observed up to 40 years and gradually increased thereafter, thus indicating positive energy balance. The mean waist to hip ratio increased with increasing age, ranging from $0.82-0.96$, indicating abdominal obesity.

The mid upper arm muscle circumference and mid arm circumference of the subjects were below normal values when compared to the Jelliffe's standards indicating that the women had low protein status from a young age and the trend continued even in the later years of life. The Triceps skin fold thickness which indicates the fat status, increased with the increasing age in the subjects.

The distribution of the subjects on the basis of body mass index and waist hip ratio is presented in Table 3.

It was observed that $60 \%$ of women in the age group of 20-30 years were in normal weight 
Table 1: Background Information of the selected women

\begin{tabular}{lr}
\hline Demographic characteristics & No. $(\%)$ \\
\hline Religion & \\
Hindu & $30(75)$ \\
Christian & $8(20)$ \\
Muslim & $2(5)$ \\
Family type & \\
$\quad$ Nuclear & $32(80)$ \\
Joint & $8(20)$ \\
Household size & \\
<4 & $15(38)$ \\
4 & $14(35)$ \\
5 to 8 & $10(25)$ \\
$>8$ & $1(2)$ \\
Number of Children & \\
None & $8(20)$ \\
1 & $15(38)$ \\
2 & $16(40)$ \\
3 & $1(2)$ \\
Education & \\
Non-Literate & $4(10)$ \\
Primary Level & $11(28)$ \\
Graduate & $12(30)$ \\
Post Graduate & $13(32)$ \\
Occupation & $20(50)$ \\
Home maker & $15(38)$ \\
Lecturer & $5(12)$ \\
Clerk & \\
\hline
\end{tabular}

range and $40 \%$ were classified under overweight category. In the later ages it was found that the trend sifted more towards overweight in the age group of $41-50$ years. $50 \%$ women in the age group of 51-60 years were categorized under normal weight and $50 \%$ under overweight. Thus, the percentile classification of the women by body mass index indicated $45 \%$ of women had above normal body mass index. The number of women having above the normal body mass index in each group ranged between 4 to 6 , which accounted to more than $40 \%$.

The waist hip ratio of the subjects showed that $70 \%$ of women under the age group of 20-30 years had abdominal obesity and $30 \%$ had Gluteal femoral obesity. $40 \%$ of women had Waist hip ratio $>0.9$ in the age group of 51-60 years there by indicating increased fat status. By waist hip ratio criteria, $68 \%$ of women (all groups combined) showed above normal levels. Thus, it was clearly observed that the fat status increased with increasing age. The increased waist hip ratio is considered as an indicator of malnutrition, as abdominal obesity is viewed as an adaptation to stress imposed by early or long term malnutrition.

Table 2: Mean \pm SD anthropometric measurements and indices of the women.

\begin{tabular}{|c|c|c|c|c|c|c|c|c|}
\hline \multirow{3}{*}{$\begin{array}{l}\text { Measurements/Indices } \\
\text { Height }(\mathrm{cm})\end{array}$} & \multicolumn{8}{|c|}{ Age group (Yrs) } \\
\hline & \multicolumn{2}{|r|}{$20-30$} & \multicolumn{2}{|c|}{$31-40$} & \multicolumn{2}{|c|}{$41-50$} & \multicolumn{2}{|r|}{$51-60$} \\
\hline & 157.9 & \pm 6.5 & 154.2 & \pm 4.0 & 154.4 & \pm 3.0 & $155.8=$ & \pm 3.4 \\
\hline Weight $(\mathrm{kg})$ & 57.3 & \pm 6.9 & 56.1 & \pm 5.6 & 59.4 & \pm 4.48 & 60.0 & \pm 0.2 \\
\hline Body Mass Index & 22.8 & \pm 2.4 & 23.5 & \pm 2.2 & 24.6 & \pm 1.8 & $24.6=$ & \pm 1.4 \\
\hline Midupper Arm circumference $(\mathrm{cm})$ & 27.0 & \pm 2.2 & 26.8 & \pm 1.7 & 25.3 & \pm 1.2 & $24.9=$ & \pm 1.2 \\
\hline Midupper muscle circumference $(\mathrm{cm})$ & 22.2 & \pm 1.7 & 21.4 & \pm 1.8 & 20.9 & \pm 0.9 & $19.0=$ & \pm 0.9 \\
\hline Triceps Skin fold $(\mathrm{mm})$ & 15.4 & \pm 1.7 & 16.1 & \pm 2.1 & 16.3 & \pm 1.3 & $18.2=$ & 2.6 \\
\hline Waist $(\mathrm{cm})$ & 78.4 & \pm 5.0 & 89.0 & \pm 5.0 & 86.1 & \pm 6.5 & $91.7=$ & \pm 12.0 \\
\hline Hip $(\mathrm{cm})$ & 96.2 & \pm 5.9 & 104.2 & \pm 4.7 & 97.3 & \pm 5.1 & $95.2=$ & \pm 7.0 \\
\hline Waist/Hip Ratio & 0.82 & $2 \pm 0.02$ & 0.85 & \pm 0.04 & 0.88 & \pm 0.02 & $0.96=$ & 0.19 \\
\hline
\end{tabular}

Table 3: Percentile classification of the women by body mass index and waist/hip ratio

\begin{tabular}{|c|c|c|c|c|c|}
\hline \multirow[t]{2}{*}{ Classification } & \multicolumn{4}{|c|}{ Age group (Yrs) No. (\%) } & \multirow{2}{*}{$\begin{array}{c}\text { All groups } \\
\text { combined No. }(\%)\end{array}$} \\
\hline & $20-30$ & $31-40$ & $41-50$ & $51-60$ & \\
\hline \multicolumn{6}{|c|}{ Body Mass Index } \\
\hline$<18.5$ & - & - & - & - & \\
\hline $18.5-24.9$ & $6(60)$ & $7(70)$ & $4(40)$ & $5(50)$ & $22(55)$ \\
\hline $25-30$ & $4(40)$ & $3(30)$ & $6(60)$ & $5(50)$ & 18 (45) \\
\hline$>30$ & - & - & - & - & - \\
\hline \multicolumn{6}{|c|}{ Waist-Hip Ratio } \\
\hline$<0.7$ & - & - & - & - & - \\
\hline $0.71-0.8$ & $3(30)$ & $2(20)$ & - & $1(10)$ & $6(15)$ \\
\hline $0.81-0.9$ & $7(70)$ & $6(60)$ & $9(90)$ & $5(50)$ & $27(68)$ \\
\hline$>0.9$ & - & $2(20)$ & $1(10)$ & $4(40)$ & 7 (17) \\
\hline
\end{tabular}


Percentile classification of the women by mid upper arm circumference, triceps skin fold thickness, and mid upper arm muscle circumference is presented in Table 4. 35\% of women regardless of the age group had low protein status as indicated by mid upper arm circumference. Mid upper arm muscle circumference, which is more specific, indicated that $55 \%$ of women had low protein status. The number of women with low protein status was found to be greater in the older age groups.

Fat status as indicated by triceps skin fold thickness was found to be normal in $50 \%$ of women (all age groups combined). The number of women having low fat stores was low and was seen only in the younger age group.

Body mass index (BMI) vis-à-vis waist hip ratio of the selected women is shown in Table 5. It was observed that $40 \%$ of the subjects with normal body mass index in the age group of 20-30 years had a waist hip ratio of 0.81-0.9 indicating abdominal obesity even with normal BMI range. This could be attributed to stress and adaptation to the same. In the later years, the trend shifted to more overweight women with increased waist hip ratio values. It was observed that regardless of body mass index class, $70 \%$ of women (all age groups combined) showed above normal waist hip ratio. This increase in both fat and energy chronic diseases.

Stress Assessment: Stress experienced by the status are risk factors for the development of women due to occupation and other factors were

computed and is presented in Figure 1. The scores were found to reduce with advancing age; with scores of 31,36 and 36 for the age groups of 21$30,31-40$ and $41-50$ years respectively. However, stress scores of women in the age group of 51-60 years reduced to 29 . This trend indicates the adaptation that people develop to stress over a period of time in later ages.

Table 5: Body mass index vis-à-vis waist/hip ratio of the selected women

\begin{tabular}{|c|c|c|c|c|}
\hline \multirow{3}{*}{$\begin{array}{l}\text { Age Group (yrs) } \\
\text { and Body mass } \\
\text { index range }\end{array}$} & \multicolumn{4}{|c|}{ Waist/Hip ratio } \\
\hline & $<0.7$ & $0.71-0.8$ & $0.81-0.9$ & $>0.9$ \\
\hline & No. (\%) & No. (\%) & No. (\%) & No. $(\%$ \\
\hline \multicolumn{5}{|l|}{$20-30$} \\
\hline$<18.5$ & - & - & - & - \\
\hline $18.5-24.9$ & - & $3(30)$ & $4(40)$ & - \\
\hline $25-30$ & - & - & $3(30)$ & - \\
\hline$>30$ & - & - & - & - \\
\hline \multicolumn{5}{|l|}{$31-40$} \\
\hline$<18.5$ & - & - & - & - \\
\hline $18.5-24.9$ & - & $1(10)$ & $6(60)$ & - \\
\hline $25-30$ & - & $1(10)$ & $1(10)$ & $1(10)$ \\
\hline$>30$ & - & - & - & - \\
\hline \multicolumn{5}{|l|}{$41-50$} \\
\hline$<18.5$ & - & - & - & - \\
\hline $18.5-24.9$ & - & $2(20)$ & $2(20)$ & - \\
\hline $25-30$ & - & $2(20)$ & $4(40)$ & - \\
\hline$>30$ & - & - & - & - \\
\hline \multicolumn{5}{|l|}{$51-60$} \\
\hline$<18.5$ & - & - & - & - \\
\hline $18.5-24.9$ & - & $2(20)$ & $3(30)$ & - \\
\hline $25-30$ & - & - & $5(50)$ & - \\
\hline$>30$ & - & - & & - \\
\hline $\begin{array}{l}\text { All groups } \\
\text { combined }\end{array}$ & - & $11(28)$ & $28(70)$ & $1(2)$ \\
\hline
\end{tabular}

Table 4: Percentile classification of the women by mid upper arm circumference, triceps skin fold and mid upper arm muscle circumference.

\begin{tabular}{|c|c|c|c|c|c|}
\hline \multirow[t]{2}{*}{ Measurements/Indices } & \multirow[b]{2}{*}{$20-30$} & \multicolumn{3}{|c|}{ Age group (Yrs) No. (\%) } & \multirow{2}{*}{$\begin{array}{c}\text { All groups } \\
\text { combined No. }(\%,\end{array}$} \\
\hline & & $31-40$ & $41-50$ & $51-60$ & \\
\hline \multicolumn{6}{|c|}{ Midupper Arm Circumference } \\
\hline$>110$ & - & - & - & - & - \\
\hline $110-101$ & $3(30)$ & $2(20)$ & - & - & $5(13)$ \\
\hline $100-91$ & $6(60)$ & $7(70)$ & $5(50)$ & $3(30)$ & $21(52)$ \\
\hline $90-70$ & $1(10)$ & $1(10)$ & $5(50)$ & $7(70)$ & $14(35)$ \\
\hline$<70$ & - & - & - & - & - \\
\hline \multicolumn{6}{|l|}{ Triceps Skin Fold } \\
\hline$>110$ & - & $2(20)$ & $1(10)$ & $4(40)$ & $7(17)$ \\
\hline $110-101$ & $3(30)$ & $1(10)$ & $2(20)$ & $2(20)$ & $8(20)$ \\
\hline $100-91$ & $4(40)$ & $5(50)$ & $7(70)$ & $4(40)$ & $20(50)$ \\
\hline $90-70$ & $3(30)$ & $2(20)$ & - & - & $5(13)$ \\
\hline$<70$ & - & - & - & - & \\
\hline \multicolumn{6}{|c|}{ Midupper Muscle Circumference } \\
\hline$>110$ & - & - & - & - & - \\
\hline $110-101$ & $3(30)$ & $1(10)$ & - & - & $4(10)$ \\
\hline $100-91$ & $6(60)$ & $6(60)$ & $1(10)$ & $1(10)$ & $14(35)$ \\
\hline $90-70$ & $1(10)$ & $3(30)$ & $9(90)$ & $9(90)$ & $22(55)$ \\
\hline$<70$ & - & - & - & - & - \\
\hline
\end{tabular}




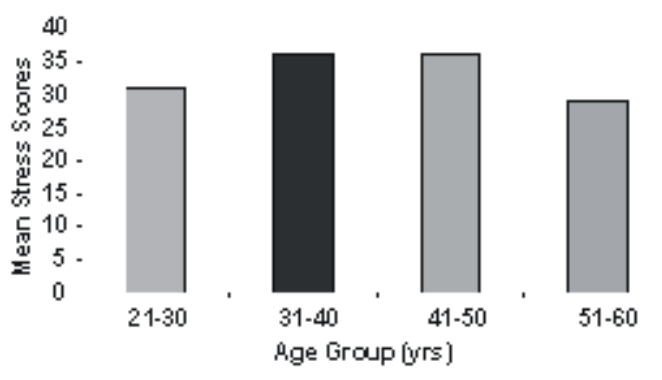

Fig. 1. Mean stress scores of the subjects.

Waist hip ratio vis- a- vis stress scores of the women is presented in Table 6 . The results indicated that the stress scores increased with the increase in waist hip ratio. $30 \%$ of the women in the age group of 20-30 had stress scores in between 31-40 and waist hip ratio was found to be $0.81-0.9$. Likewise $60 \%$ of women in the age group of 31-40 and 41-50 years had stress scores between $31-40$ and the waist to hip ratio was found to be $0.81-0.9 .30 \%$ of women in the age group of 51-60 years had stress scores between 31-40 and the waist hip ratio was found to be $>0.9$.

Energy Intake and Expenditure: The intake of energy was observed to be less than the recommended energy intake for each group. The energy intake and expenditure as compared to recommended energy intake of the Women is shown in Figure 2.

Energy intake, resting metabolic energy compared to recommended energy intake of the subjects is shown in Table 7 and time spent on various activities is presented in Table 8 . The energy expenditure in physical activity decreased with increasing age. It was observed that most women spent their time in sitting. Maximum amount of time was spent on rest and sleep and this time spent increased with increasing age. The gain in weight with the age and increased waist hip ratio can be attributed to the lesser energy expended by the subjects as indicated by the results.

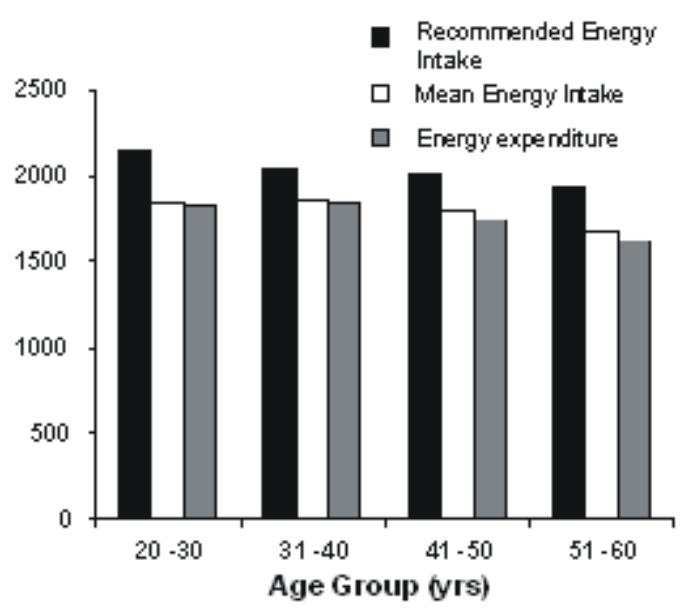

Fig. 2. Energy intake and expenditure as compared to recommended energy

Table 7: Energy intake and resting metabolic energy as compared to recommended energy intake of the women

\begin{tabular}{lccc}
\hline $\begin{array}{l}\text { Age } \\
\text { group } \\
\text { (yrs) }\end{array}$ & $\begin{array}{c}\text { Energy } \\
\text { intake }\end{array}$ & $\begin{array}{c}\text { Resting } \\
\text { metabolic } \\
\text { energy }\end{array}$ & $\begin{array}{c}\text { Recommended } \\
\text { energy } \\
\text { intake }\end{array}$ \\
\hline $20-30$ & $1840 \pm 405$ & $1269 \pm 103$ & $2138 \pm 177$ \\
$31-40$ & $1850 \pm 270$ & $1253 \pm 55$ & $2038 \pm 106$ \\
$41-50$ & $1795 \pm 125$ & $1278 \pm 46$ & $2009 \pm 92$ \\
$51-60$ & $1675 \pm 220$ & $1286 \pm 50$ & $1932 \pm 75$ \\
\hline
\end{tabular}

Computed energy expenditure of the women measured by pedometer as compared to factorial method is shown in Table 9. The difference between the values for energy expended recorded by either method did not differ significantly from each other and was within a magnitude of $10 \%$ variation. The difference in kilocalories spent in physical activity were within a difference of 100 kilocalories except for the subjects aged 31-40 and 51-60 years, where the difference was found to be 121 and 124 kilo calories respectively. Subjects (>31 years) showed higher energy intake compared to energy expenditure. A significant

Table 6: Waist-Hip Ratio vis -a -vis stress scores of the women by their age group.

\begin{tabular}{|c|c|c|c|c|c|c|c|c|c|c|c|c|}
\hline \multirow{4}{*}{$\begin{array}{l}\text { Waist-Hip } \\
\text { Ratio categor }\end{array}$} & \multicolumn{12}{|c|}{ Age group (years) } \\
\hline & \multicolumn{3}{|c|}{$20-30$} & \multicolumn{3}{|c|}{$31-40$} & \multicolumn{3}{|c|}{$41-50$} & \multicolumn{3}{|c|}{$51-60$} \\
\hline & \multicolumn{12}{|c|}{ Stress scores No. (\%) } \\
\hline & $0-20$ & $21-30$ & $31-40$ & $0-20$ & $21-30$ & $31-40$ & $0-20$ & $21-30$ & $31-40$ & $0-20$ & $21-30$ & $31-40$ \\
\hline 0.7 & & - & - & - & - & - & - & - & - & - & - & - \\
\hline $0.7-0.8$ & $2(20)$ & $1(10)$ & - & - & $2(20)$ & - & - & - & - & - & $1(10)$ & - \\
\hline $0.81-0.9$ & - & $4(40)$ & $3(30)$ & - & $1(10)$ & $6(60)$ & - & $4(40)$ & $6(60)$ & $1(10)$ & $4(40)$ & - \\
\hline$>0.9$ & - & - & - & - & - & $1(10)$ & - & - & - & - & $1(10)$ & $3(30)$ \\
\hline
\end{tabular}


Table 8: Daily time spent for different household activities by the women

\begin{tabular}{|c|c|c|c|c|c|}
\hline \multirow[t]{3}{*}{ Activity } & \multicolumn{5}{|c|}{ Age group (Yrs) } \\
\hline & \multicolumn{5}{|c|}{ Time spent (minutes) } \\
\hline & $20-30$ & $31-40$ & $41-50$ & $51-60$ & p-value \\
\hline Food preparation & $142 \pm 75$ & $117 \pm 68$ & $149 \pm 51$ & $125 \pm 29$ & $0.1770^{\mathrm{NS}}$ \\
\hline Cleaning vessels & $40 \pm 12$ & $33.5 \pm 12$ & $32 \pm 11$ & $28 \pm 8$ & $0.5245^{\mathrm{NS}}$ \\
\hline washing cloths & $25 \pm 13$ & $32 \pm 10$ & $19 \pm 7$ & $10 \pm 5$ & $0.0069^{\mathrm{s}}$ \\
\hline Total household activities & $207 \pm 100$ & $182 \pm 90$ & $200 \pm 70$ & $163 \pm 37$ & $0.1021^{\mathrm{NS}}$ \\
\hline Child care & $164 \pm 35$ & \pm 44 & 0 & 0 & $0.0000^{\mathrm{s}}$ \\
\hline Personal care & $48 \pm 6$ & \pm 9 & $50 \pm 10$ & $48 \pm 8$ & $0.9827^{\mathrm{NS}}$ \\
\hline Recreation & $233 \pm 51$ & \pm 47 & $217 \pm 42$ & $272 \pm 37$ & $0.0000^{\mathrm{s}}$ \\
\hline Rest and Sleep & $712 \pm 42$ & \pm 31 & $842 \pm 82$ & $865 \pm 75$ & $0.0001^{\mathrm{s}}$ \\
\hline Office work & $318 \pm 14$ & \pm 28 & $343 \pm 13$ & $337 \pm 9$ & $0.7954^{\mathrm{NS}}$ \\
\hline
\end{tabular}

S- Significant NS- Not Significant

Table 9: Energy expenditure of the women measured by pedometer as compared to factorial method

\begin{tabular}{|c|c|c|c|c|c|c|c|}
\hline \multirow[t]{2}{*}{$\begin{array}{l}\text { Age group } \\
\text { (yrs) }\end{array}$} & \multicolumn{2}{|c|}{$\begin{array}{c}\text { By pedometer } \\
\text { days }\end{array}$} & \multirow[t]{2}{*}{ Mean } & \multicolumn{2}{|c|}{$\begin{array}{c}\text { By factorial method } \\
\text { days }\end{array}$} & \multirow[t]{2}{*}{ Mean } & \multirow{2}{*}{$\begin{array}{c}\text { Difference } \\
\text { between } \\
\text { methods } \\
\text { (Kcal) }\end{array}$} \\
\hline & 1 & 2 & & 1 & 2 & & \\
\hline $21-30$ & 1724 & 1714 & 1719 & 1805 & 1831 & 1818 & -99 \\
\hline $31-40$ & 1685 & 1746 & 1716 & 1852 & 1819 & 1836 & -121 \\
\hline $41-50$ & 1636 & 1640 & 1638 & 1721 & 1760 & 1741 & -103 \\
\hline $51-60$ & 1508 & 1496 & 1502 & 1611 & 1641 & 1626 & -124 \\
\hline
\end{tabular}

*NS-Not Significant

$\leq \mathrm{P}=0.0006$

finding of the study appears to be the underestimation of energy expenditure in all age groups when measured by a pedometer. However, this difference is consistent within a range of 87124 kilocalories. This may perhaps be attributable to the greater proportion of fat being deposited around the abdomen in case of women advancing age (Mohan and Deepa 2006)

\section{DISCUSSION}

The results of the present study are indicative of the fact that the body weight tends to rise as the age advances. The body mass index gradually showed an increase from 22.8 to $24.6 \mathrm{~kg} / \mathrm{m}^{2}$ in the women. Recent studies have established lower limits for ideal body mass index for Asian Indian population. It was shown for urban Indian population that with a body mass index of $>23$ $\mathrm{kg} / \mathrm{m}^{2}$, the risk for diabetes was significant for both the genders. Various studies have confirmed that body mass index for an Indian should be below $23 \mathrm{~kg} / \mathrm{m}^{2}$ to maintain health and World health organization recommends a body mass index of $18.5-22 \mathrm{~kg} / \mathrm{m}^{2}$ which has been considered healthy for Asian population. Further with the increase in weight there is a tendency to develop insulin resistance and hyperinsulinemia which may lead to diabetes (Ramachandran 2004).

Though the waist hip ratio of the subjects showed an increase with age, $70 \%$ of subjects had abdominal obesity at a younger age. Excess fat in particular abdominal fat is a harbinger of several adverse metabolic consequences, including hyperinsulinemia, impaired glucose tolerance, hyperlipidemia and prothrombic tendency. Insulin resistance is commonly observed in Asian Indians and it precedes the development of coronary artery disease (Dudeja et al. 2001).

It is also hypothesized that stress - physiological or environmental results in increased cortisol levels which seems to favor the redistribution of fat to the Abdomen (Anon 1994).

In the present study, it was found that the subjects spent most of their time sitting rather than walking and hence the gain in weight and increased abdominal girth can be correlated to the reduced physical activity of the subjects.

It has been suggested that fat distributed in the abdominal region, particularly visceral fat is more metabolically important than other fat depots. Studies have clearly indicated that visceral fat is associated with diabetes. Hence abdominal adiposity assessed using waist circu- 
mference is considered to be more appropriate to predict metabolic disorders than generalized adiposity assessed by body mass index.

Further, Indians also tend to have excess body fat, abdominal and truncal adiposity. For any given waist circumference, it is seen that Indians have increased body fat accumulation and in turn for any given body fat, there may be an increased insulin resistance (Mohan and Deepa 2006)

In the present study it was clearly observed that the indicators of fat status i.e. waist to hip ratio and triceps skin fold thickness increased with increasing age while mid upper arm circumference/mid muscle arm circumferenceindicators of protein status decreased. The energy expenditure was less compared to energy intake thus indicating positive energy balance.

It is found that rate of loss of lean body mass and reserve capacity or organ function changes are linear from age 20 onwards. Hence it is likely that the chronic diseases which accounts for the morbidity in later life may have their pathological onset many decades earlier. Another aspect of nutritional status which has linkages to some of the chronic diseases associated with aging, and perhaps to the aging itself, is energy balance (Robert and Mc Gandy 1982).

Thus, the present study shows that the low protein, high fat status of the selected women along with increased waist hip ratio increases the risk of women to chronic diseases like diabetes, cardiovascular diseases and arthritis. Studies such as these are required to promote optimum health and nutrition in women who are the care takers of the family.

\section{ACKNOWLEDGEMENT}

The authors express sincere thanks to the Titan Industries Limited, Bangalore for providing pedometers to conduct the study and also thank Ms.G.Sumathi, Statistical Assistant, National
Tuberculosis Institute, Bangalore for her kind help in analyzing the data statistically.

\section{REFERENCES}

Anon 1994.Tighten your belt! Five insidiously clever ways to flatten the spare tyre. J Amer Assoc, 6(7): 28-31.

Capoor I, Chetna 2000. Women and Nutrition - Victims or decision makers. Paper presented at the Symposium on Nutrition and Development at Basel Switzerland, Nov 30.

Dudeja V, Misra AM, Pandey R, Devina G, Kumar G, Vikram NK 2001. BMI does not accurately predict overweight in Asian Indians in Northern India. British Journal of Nutrition, 86: 105-112.

Encyclopedia of Food Science 1993. Food Technology and Nutrition, 5: 32-88.

FAO/WHO/UNO (Joint) 1985.Expert consultation on Energy and protein requirements. World Health Organization Technical Report, 724. Geneva: WHO.

Gopalan C, Shastry BV, Balasubramanian SV 1993. Nutritive Value of Indian Foods Indian Council of Medical Research (ICMR) Publications. Hyderabad: National Institute of Nutrition.

Indian Council of Medical Research (ICMR) 1987. Report of an Expert Committee on Recommended Dietary Allowances for Indians. New Delhi: Indian Council of Medical Research (ICMR).

Jelliffee DB 1966. The Assessment of the Nutritional Status of the Community. Geneva: WHO.

Mishra Vinod 2004. Effect of obesity on asthma among adult Indian women. Population and Health Series, \#115 January.

Mohan V, Deepa R 2006.Obesity and abdominal obesity in Asian Indians. Indian J Med Res, 123: 593-596.

Ramachandran A 2004. Diabetes and Obesity- The Indian angle. Indian J Med Res, 120: 437-439.

Rao Shobha 2001. Nutritional status of the Indian population, Indian Academy of Sciences. J Bio Sci, 26(4 Suppl.): 481-489.

Robert B, Mc Gandy MD 1982.Methodological aspects of nutritional surveys of young and middle- aged adults. American Journal of Clinical Nutrition, 35: $1269-1272$.

Sammel MD, Grisso JA, Freeman EW, Hollander Lori, Liu Li, Liu Shinlan, Nelson DB, Battistini M 2003. Weight gain among women in the late reproductive years. Family Practice, 20: 401-409

United Nations University 2006. Micronutrient fortification, World food programme experiences and ways forward. Food and Nutrition Bulletin, 27(1): 67-75. 